Review

\title{
Oncolytic Bacteria and their potential role in bacterium-mediated tumour therapy: a conceptual analysis
}

\author{
Yuqing Wang1, Wenxuan Guo1, XiaoLi Wu², Ying Zhang3, Ciaran Mannion"4, Anatoli Brouchkov5, 6 , \\ Yan-Gao Man ${ }^{7 凶}$, Tingtao Chen ${ }^{1 凶}$ \\ 1. Institute of Translational Medicine, Nanchang University, Nanchang, Jiangxi 330031, PR China \\ 2. JiangXi university of traditional Chinese medicine, College of basic medicine, Nanchang 330000, PR China \\ 3. Department of Molecular Microbiology and Immunology, Bloomberg School of Public Health, Johns Hopkins University, Baltimore, MD, USA \\ 4. Hackensack University Medical Center, Hackensack, NJ, USA \\ 5. Lomonosov Moscow State University, Leninskie Gory, Moscow 119991, Russia \\ 6. Tyumen State University, Volodarskogo 6, Tyumen 625003, Russia \\ 7. Department of Pathology, Hackensack Meridian Health-Hackensack University Medical Center, NJ, USA
}

$\triangle$ Corresponding authors: Dr. Tingtao Chen Institute of Translational Medicine, Nanchang University, Nanchang, Jiangxi 330031, PR China; e-mail: chentingtao1984@163.com; Tel: +86-791-83827170; Dr. Yan-gao Man Department of Pathology, Hackensack Meridian Health-Hackensack University Medical Center, NJ, USA; e-mail: yanmann@aol.com;

(c) The author(s). This is an open access article distributed under the terms of the Creative Commons Attribution License (https://creativecommons.org/licenses/by/4.0/). See http://ivyspring.com/terms for full terms and conditions.

Received: 2019.04.11; Accepted: 2019.06.11; Published: 2019.07.23

\begin{abstract}
As the human microbiota has been confirmed to be of great significance in maintaining health, the dominant bacteria in them have been applied as probiotics to treat various diseases. After the detection of bacteria in tumours, which had previously been considered a sterile region, these bacteria have been isolated and genetically modified for use in tumour therapy. In this review, we sum up the main types of bacteria used in tumour therapy and reveal the mechanisms of both wild type and engineered bacteria in eliminating tumour cells, providing potential possibilities for newly detected, genetically modified, tumour-associated bacteria in anti-tumour therapy.
\end{abstract}

Key words: Engineered bacteria, Tumour therapy, Human microbiota, Probiotics

\section{Introduction}

The adult human body is composed of $10^{13}$ eukaryotic cells, while approximately ten times as many microorganisms reside on the surface and inside the body [1]. Various microorganisms interact with each other, constituting the microbiota of the human body, which is essential for human health. Four dominant microbiota including gut, vagina, oral cavity and skin have been regarded taking charge of different aspects of human health [2-5]. Dysbiosis of these microbiota is associated with continuous stimulation of the immune response and the production of bacterial metabolites-derived carcinogens, which increase the risk of acquiring various diseases, e.g. inflammatory bowel disease (IBD), allergy, cancer, diabetes, obesity and neurodevelopmental disorders [6-7].
Commensal microbiota exists on the surface or inside the body. Bacteria have also been detected in some regions that had previously been considered sterile, including the placenta, breast milk, tumours and blood. This suggests the potential existence of probiotics or pathogens in those areas and may provide clues for the diagnosis and treatment of tumours [8-10].

In the early $19^{\text {th }}$ century, wild-type Clostridium perfringens was first detected in patients with cancer, and live anaerobic bacteria were injected into animal models to examine their oncolytic effects [11]. Then, 'smarter' bacteria (e. g. Salmonella typhimurium, Listeria monocytogenes) were designed to kill tumour cells with the development of advanced gene engineered techniques via the expression of tumour-related 
antigens, pro-drug-converting enzymes or agents toxic to tumours [12-14]. Therefore, it is an interesting topic to reveal the microbial composition living in tumour and elucidate their potentialities as oncolytic bacteria or bacteria that secrete metabolites or proteins that are directly toxic to cancer cells [15].

\section{Bacteria eliminating tumours - History, mechanisms and therapeutic effects}

Cancer is a devastating disease defined by abnormal cell growth with the potential to invade and spread to other parts of body, which is called metastasis [16]. Solid tumours account for approximately $90 \%$ of all cancers and are characterised by aberrant vascular formation [17]. Formation of arteriovenous shunts and blunt ends leads to less delivery of oxygen and nutrients to overall neoplastic tissues [18]. Tissues surpassing the limitation of blood delivery become hypoxic or even necrotic, which is a typical characteristic of solid tumours and a distinguishable feature between normal and neoplastic tissues [19].

All tumours contain two basic components: the parenchyma and stroma [20]. The parenchyma is made up of transformed or neoplastic cells and it mainly determines the behaviour of tumour; the stroma is composed of host-derived and non-neoplastic cells, made up of connective tissue, blood vessels, and host-derived inflammatory cells [20]. These two compartments of the tumour create radically different microenvironments that can profoundly influence therapeutic approaches [21]. For instance, the sensitivity of hypoxic regions in the tumour to ionic radiation is one third that of normal tissues, with half the normal concentration of oxygen [22]. The hypoxic region of the tumour may also be insensitive to chemical agents due to an insufficient blood supply [23]. From another point of view, conventional therapies for treating cancers including radiotherapy and chemotherapy have low specificities, reflected in eliminating both normal cells and tumour cells, resulting in the suppression of the immune system [24]. Thus, innovative therapies such as targeting the hypoxic area of the tumour need to be further explored for more specific and efficient cancer treatments.

The existence of bacteria in tumours provides a potential new direction for cancer therapy using wild type or engineered bacteria. The first breakthrough in cancer therapy dates back to 1813, when Vautier observed tumour regression in patients with gas gangrene after infection of $C$. perfringens [11]. Several decades later, a pioneering New York surgeon,
William B, Coley, dedicated himself to curing cancer patients using immunotherapy after the loss of his first cancer patient, a young girl with a sarcoma in her right arm [25]. When he looked through the medical records of the hospital, he noticed a 7-year-old patient who had experienced the regression of a recurrent sarcoma after the infection of erysipelas [25]. Then, he began to search the medical literature for similar situations and found the most frequent combination of infectious disease and cancer were sarcoma patients with erysipelas [25]. This incidental discovery elicited continuous studies on curing cancers via the direct injection of streptococcal broth cultures of heat-killed Streptococci, finally reaching the achievements of Coley's toxin (heat-killed Streptococcus and Serratia marcescens) [26]. In the next 40 years, he treated hundreds of patients with inoperable sarcomas using immunotherapy [27]. These findings elicited interest in exploring the therapeutic effects of anaerobic bacteria existing in hypoxic regions of neoplastic tissues. Over the years, a series of obligate or facultative anaerobic bacteria have been tested, targeting tumour cells and inducing tumour regression. They may exert their anti-tumour effects via a number of mechanisms, including direct toxicity to tumour cells via type III secretions, in which cytotoxic peptides are injected directly into the target cell's cytoplasm [28,29]; the facilitation of a non-specific immune response; the depletion of necessary nutrients; and the alteration of the tumour microenvironment by bacterial colonisation. Additionally, immunomodulatory effects including the stimulation of the dendritic cells or alterations in $\mathrm{T}$ helper cell polarisation could play a role [30,31].

The characteristics of anaerobic bacteria living in hypoxic tumour tissues allows them to exert anti-tumour effects against those cells that are resistant to other anti-cancer therapies such as radiation and chemotherapy. Bacterial motility promotes their dispersion inside the tumour and to more distant sites, which amplifies their function to some extent. Meanwhile, bacteria also have the ability carry specific genes due to their large genome size and ease of genetic manipulation. Transgenes coding for cytokines, enzymes, and immunogens can all be expressed following bacterial infection. Clostridium spp., Bifidobacterium spp., Salmonella typhimurium, Vibrio cholera, Listeria monocytogenes, and Bacillus spp. are bacteria that have been most widely identified inside tumours and have the ability to kill tumour cells in a natural or genetically modified form, indicating their potential for therapeutic effects in anti-cancer therapy (Fig. 1). 


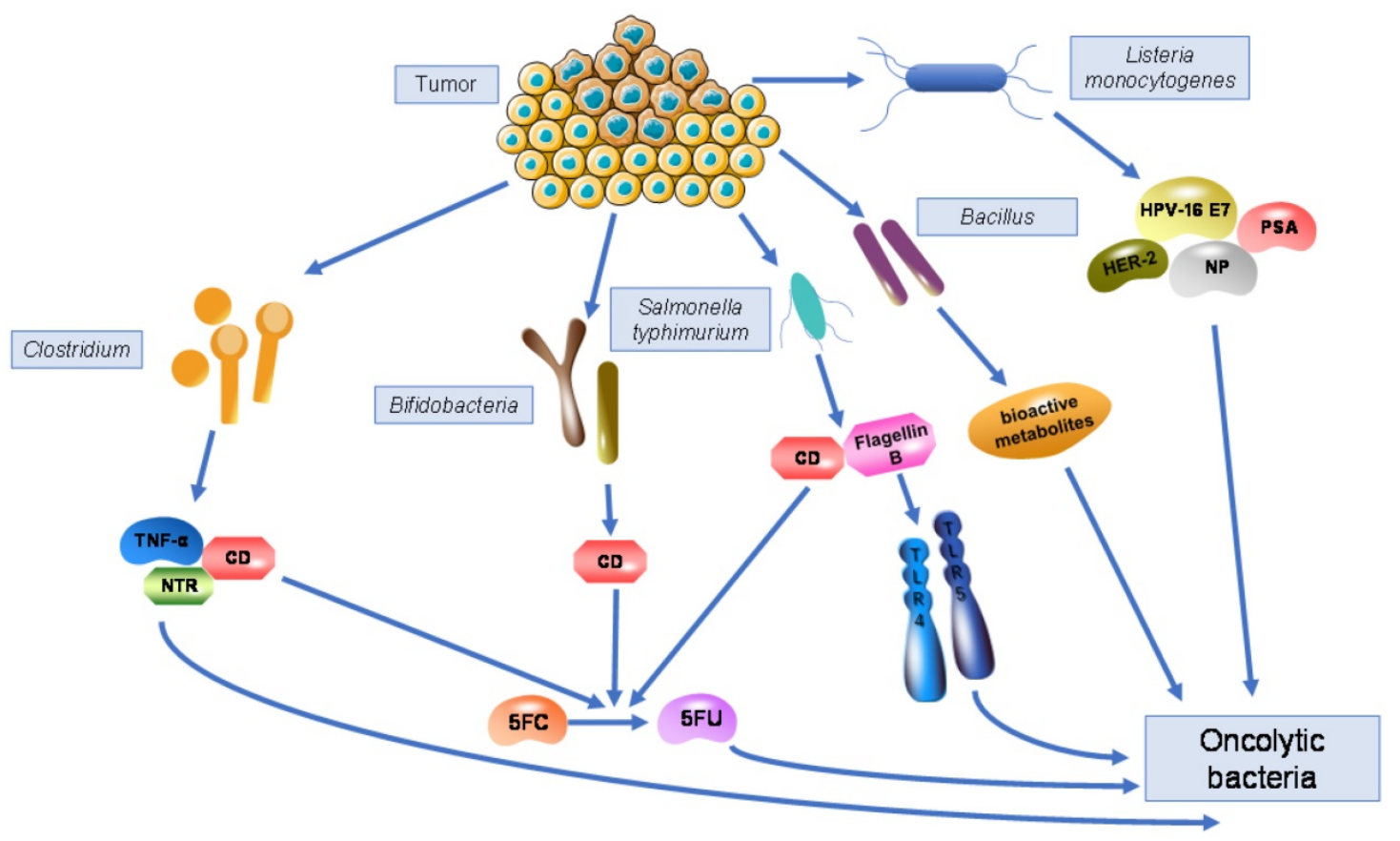

Figure 1. Bacteria living in tumours and their mechanisms as oncolytic bacteria. Genetically modified Clostridium are able to express cytosine deaminase (CD), which can convert the non-toxic pro-drug 5FC into the toxic antineoplastic drug 5FU, similar to Bifidobacteria and Salmonella typhimurium. Engineered Clostridium can also express nitroreductase (NTR) or TNF-a, killing tumour cells by converting pro-drugs or producing cytokines. Recombinant Salmonella typhimurium expresses flagellin B to activate TLR4 and TLR5, triggering stronger immune response to kill tumour cells. Engineered Listeria monocytogenes acts as a vaccine vector by expressing various antigens including NP, HPV-16 E7, PSA, and HER-2, generating cell-mediated immunity to eliminate tumours. Bacillus produces various bioactive metabolites against cancer cells.

\subsection{Clostridium}

Clostridium is a genus of obligate anaerobic, Gram-positive bacteria that has the ability to produce endospores [32]. The normal, reproducing cell of Clostridium is called the vegetative form. Which has a rod shape. Several strains are considered to be common pathogenic bacteria, including Clostridium botulism, C. difficile, C. perfringens, and C. tetani [33]. After Vautier found that patients with gas gangrene seemed to be cured following infection with $C$. perfringens, the toxicity and antitumour effect of many strains of Clostridium were tested using animal models [34]. In 1927, Torrey and Kahn first reported the ability of $C$. histolyticus to lyse tumours by injecting sterile filtrates of the bacteria directly into tumours in rats, resulting in a considerable number of tumours limited to a diameter of $2 \mathrm{~cm}$ [35].

Later, in 1935, Connell found that the proteolytic enzymes secreted by $C$. histolyticus were able to degrade tumour cells preferentially without influencing normal tissue [36]. Parker et al. in 1947 observed the apparent lysis of sarcomas in rat models after the intratumoural inoculation of spores of $C$. histolyticus [37]. The precise selectivity of Clostridia to hypoxic/necrotic regions was further identified by Malmgren and Flanigan in 1955 [38]. Spores of the C. tetani were injected intravenously into tumour-bearing mice and non-tumour-bearing mice; the tumour-bearing mice died within $48 \mathrm{~h}$ after injection of the spores while the non-tumour-bearing control mice survived without any tetanus symptoms throughout the whole study [38]. These experimental phenomena indicated the complete germination of spores and the production of tetanus toxins within tumour tissues, subsequently verified by microscopic examination of tumour and normal tissue sections. A non-pathogenic strain of Clostridium named $C$. butyricum M55 was isolated from the soil, then later renamed as C. oncolyticum; it is now classified as $C$. sporogenes (ATCC13732) [39]. It may have the same ability to lyse tumours.

Aiming at finding an unharmful Clostridium oncolytic therapy, J. R. Möse and G. Möse injected spores of non-pathogenic proteolytic strain $C$. butyricum intravenously into mice transplanted with solid Ehrlich carcinomas [39]. The tumours then lysed, discharging a brown liquid necrotic mass [39]. However, some experimental animals still died after the extensive lysis of tumours as remaining viable cells led to the regrowth of them. Under these circumstances, in order to target the remaining cancer cells, combination therapies were created. The combination of spore administration and various chemotherapeutic agents including 5-fluorodeoxyuridine and cyclophosphamide resulted in a more obvious reduction in tumour weight $[40,41]$. 
Moreover, the combination of Clostridium spores with local irradiation and high-frequency hyperthermia increased the level of hypoxia in the tumour and led to an evident increase in the survival rate of mice bearing melanomas [42]. The effectiveness of antitumour therapy could also be achieved by decreasing the oxygen level of the air breathed by tumour-bearing mice to only $11-12 \%$. Owing to the effectiveness of combined therapies, the tumour lysed more thoroughly, but the tumour cells could not be eliminated completely.

In 1967, J. R. Möse and G. Möse injected themselves with spore suspensions of $C$. sporogenes ATCC 13732 and verified its non-pathogenicity in humans [43]. Further experiments indicated the limitations of the intravenously injecting Clostridium spores in five patients with neoplastic disease. Oncolysis only occurred in large tumours, not in the surrounding normal tissues or smaller tumours and metastases [43]. The intratumoural injection of spores in patients with glioblastoma should be accompanied by surgery to remove the lysis abscess in the case of rupture as it may lead to death [44]. Clostridium spore injection only affects large tumours rather than small tumours and metastases, and it cannot clear all tumour cells, which may result in the regrowth of the tumour or the discontinuation of clinical trials.

As soon as recombinant DNA techniques and specific transformation protocols for Clostridium became available, much effort was put into the development of Clostridium strains producing anti-tumour proteins. Because of their exquisite specificity to germinate in the hypoxic/necrotic regions of solid tumours, these strains could be used as vector systems for the specific delivery of therapeutic proteins in the tumour microenvironment [45]. In preclinical studies, Schlechte and Elbe were the first to attempt the combination of the $C$. sporogenes ATCC 13732 with the Escherichia coli-derived gene coding colicin E3, a bacteriocin with cancerostatic properties [46]. Later, genetically modified C. beijerinckii was capable of expressing $E$. coli enzymes nitroreductase and cytosine deaminase, which converts the non-toxic pro-drugs CB1954 and 5-fluorocytosine into toxic anti-cancer compounds, which diffuse into the tumour and trigger cell death by interfering in DNA replication/transcription $[45,47]$. In 2001, the same principle of producing cytotoxic agents was applied to recombinant Clostridium with the promotor recA driving the expression of the gene encoding for the cytokine TNF-a after 2 Gy of irradiation, indicating a promising prospect for gene targeting and ionising radiation [48]. To select the anaerobic bacterial strain with the highest efficacy in growing within avascular tumours, a systemic assessment was done among the 26 strains, and C. novyi was the most promising [42]. The spores of engineered C. novyi without its lethal toxin (C. novyi-NT) were intravenously injected with chemotherapeutic drugs, resulting in extensive necrosis of transplanted tumours within 24 hours [49]. DNA damaging agents (Cytoxan, mitomycin) as well as tumour vascular collapsing agents (Dolastatin-10) were combined with $C$. novyi-NT and led to the dramatic regression of transplanted tumours in mice [49]. This strategy was termed combination bacteriolytic therapy (COBLT) and may lead to an innovative direction for cancer therapy by $i, v$. injection of C. novyi-NT recombinated with specific anti-tumour genes.

\subsection{Bifidobacteria}

Bifidobacterium is a genus of Gram-positive, obligate anaerobic bacteria. They are naturally present in the dominant colonic microbiota, and represent up to $25 \%$ of the cultivable faecal bacteria in adults and $80 \%$ in infants [50]. It is regarded as potentially health-enhancing bacteria in the human gut and its dominance in the faeces of breast-fed babies is considered to impart protection against infections [51]. As a probiotic agent, Bifidobacterium is present in fermented foodstuffs (e.g., yogurt, cheese, olives and other fermented vegetables) and its safety is supported by those foodstuffs and growing knowledge about Bifidobacteria taxonomy and physiology [52].

Bifidobacterium is considered as a safe candidate carrier due to the bacterial medicine Bifidobacterium bifidum (LacB; Nikken Kagaku, Tokyo, Japan), which is prescribed for patients in Japan. Experiments showed that after the intravenous administration of a Lac B suspension in tumour-bearing mice, they did not show any adverse symptoms [53]. The bacteria completely disappeared in non-malignant tissues such as the liver, kidney, spleen, lung, blood and bone marrow within in 24 to 96 hours and the bacteria only grow in tumour tissues [54]. Later, a more advanced tumour-targeting plasmid vector (pBLES100-S-eCD) was accomplished by the combination of a promoter from a gene coding histone-like protein and the cytosine deaminase gene of E. coli (e-CD) [55]. The function of this gene is to concert 5-fluorocytosin $(5 \mathrm{FC})$, an antifungal reagent of low toxicity, into 5 -fluorouracil (5FU), a common anticancer drug specifically for targeting tumour tissues [55]. In early cancer treatment experiments, autochthonous tumours of rat breast cancer were developed with the carcinogen 7,12-dimethylbenz(a)anthracene [56]. The suppression of tumour growth was observed in the group treated with the injection of bacteria 
transformed by e-CD-expression vectors, and when the pro-drug 5FC was given orally [56]. The same treatment system was also found to be efficient on human breast cancers transplanted into immunologically-deficient nude mice [57].

In order to examine the immunological reactions, further tests concentrated on inflammatory cytokine levels in the blood after the i.v. injection of B. longum carrying the e-CD expression vector or non-pathogenic E. coli as a control. The results showed that no inflammatory cytokines were induced by the injection of $B$. longum while $E$. coli induced the cytokines such as the interleukin-6 (IL-6), IL-1 $\beta$ and IL-18. This experiment demonstrated that the genetically modified $B$. longum did not trigger intense immunological response, thus verifying its safety. Similar results have also been reported showing that Bifidobacteria induces low levels of IL-12 and TNF-a in the blood regardless of the strain used. In contrast, strains Lactobacillus possess different abilities to induce IL-12 and TNF-a [58].

\subsection{Salmonella typhimurium}

Salmonella typhimurium is a pathogenic, Gram-negative, facultative anaerobic bacterial species that can be found predominantly in the intestinal lumen. Its toxicity is due to an outer membrane consisting of abundant lipopolysaccharides (LPS) which protect the bacteria from the environment. The LPS is made up of an O-antigen, a polysaccharide core and lipid $\mathrm{A}$, which connects it to the outer membrane [59]. Lipid A is made up of two phosphorylated glucosamines which are attached to fatty acids. These phosphate groups determine bacterial toxicity. Animals carry an enzyme that specifically removes these phosphate groups to protect themselves from these pathogens. The O-antigen, being on the outermost part of the LPS complex is responsible for the host immune response [60]. S. typhimurium has the ability to undergo acetylation of this O-antigen, which changes its conformation and makes it difficult for antibodies to recognise [61].

Wild-type Salmonella, in particular $S$. typhimurium, have been detected as the pathogen that causes self-limited enteritis in most healthy adults, infects many mammalian species and can easily be manipulated to carry therapeutic transgenes [62]. $S$. typhimurium exists as a facultative anaerobe, allowing it to survive in both oxygenated and hypoxic conditions; thus, it may colonise both small metastatic lesions and larger tumours. In 1997, Pawelek et al. found that Salmonella has the ability to infect and accumulate within implanted tumours in mice, achieving the ratios of concentrations in tumour/normal tissue up to 1,000:1, which indicates that this may be a clinically useful anti-cancer agent [63]. However, the toxicity of wild-type $S$. typhimurium limits its potential in preclinical studies of tumour therapy. For the earliest detection of attenuated Salmonella, Bacons and his co-workers reported the Salmonella with auxotrophic mutants had a great reduction in virulence $[64,65]$. To develop a clinical candidate with higher safety, a wild-type $S$. typhimurium has been attenuated by partial deletion of the $m s b B$ gene, which is responsible for addition of a terminal myristyl group to lipid A [66]. This mutant leads to a diminished ability of S. typhimurium to induce the secretion of TNF-a in vitro in human monocytes and in vivo after the administration to mice and pigs [67]. For further safety consideration, the bacteria were further attenuated by partial deletion of the purI gene, creating a growth requirement for external sources of purines, whose concentrations are high in the interstitial tissues in the tumour environment with the attenuated toxicities identified in mutant strains [68]. Genetically modified $S$. typhimurium (VNP20009) has a safety profile of possessing partial deletion of both $m s b B$ and purI genes, which limits the toxicity of $S$. typhimurium in normal tissues while retaining the tumour-targeting and tumour-inhibiting properties [68-70].

In preclinical experiments, the ability of attenuated Salmonella spp. to retard tumour growth was assessed in various animal models. When single-cell suspensions of Salmonella were intravenously injected into animals with $4-5 \mathrm{~mm}$ tumour or in the case of metastatic models, the growth of the tumour and dissemination of metastases were strongly inhibited for a prolonged period [71]. Several models showed a longer survival time; however, the tumour eventually recurred, leading to the death of the animals [71]. Site-related and systemic toxicities reported in preclinical studies of VNP20009 were not observed unless the doses of suspensions were excessive [72]. Meanwhile, the specificity of VNP20009 accumulating preferentially inside tumours over the liver was also observed in different types of tumour-bearing mice at a ratio $\geq 1000: 1$. However, in normal mice and cynomolgus monkeys, VNP20009 is rapidly cleared from a peak level to undetectable in blood within $24 \mathrm{~h}$, which indicates little potential for septic shock.

The mechanisms that lead to the accumulation of bacteria in tumours compared to relative lower levels in other tissues may include the different vascular structures and blood flow patterns, which may lead to the entrapment of bacteria in tumours. Additionally, bacteria may also attach or be phagocytosed by immune cells transferred to tumour sites [73].

Concerning the clinical trials about attenuated 
Salmonella, recent studies show better therapeutic effects in combination with other anti-tumour therapies. As the bacteria alone could only delay the tumour growth rather than inhibit the recurrence of tumours, more rigorous genetic modulations could be applied to $S$. typhimurium to enhance the tumour inflammatory response. These strategies include the delivery of genes coding for cytokines, pro-drug-converting enzymes and agents toxic to tumour. For instance, engineered attenuated $S$. typhimurium is able to express cytosine deaminase, which could possibly catalyse the non-toxic pro-drug 5-fluorocytosine to anti-tumour drug fluorouracil, which mimics uracil in tumour cell replication and inhibit this process [13]. Another mechanism that is worth paying attention to is the activation of immune response induced by intravenously injection of genetically recombinant $S$. typhimurium detected in mice models. In this situation, an attenuated $S$. typhimurium was engineered to express a Toll-like receptor (TLR) 5 agonist Vibrio vulnificus flagellin B protein $(\mathrm{FlaB})$, leading to the recognition of lipopolysaccharide on the surface of the $S$. typhimurium and triggering an immune response inside the tumour; the efficacy was stronger than with a single TLR4 or TLR5 agonist [74]. In this experiments, scientisits found that TLR4 signalling pathway is prerequisite in triggering the anti-tumour immune response and FlaB/TLR5 pathway augment this reaction [74]. This process is achieved by initial colonization of the bacteria which recruits abuntdant immune cells including macrophages and neutrophils via TLR4 signalling pathway and further activation of these immune cells triggered by TLR5 signalling mediated by the secretion of FlaB [74], Other engineered $S$. typhimurium expressing the cytokine LIGHT was injected intravenously to mice models of both primary and established pulmonary metastases, carrying out anti-tumour effects by binding to LIGHT receptors, transducing signals to induce the expression of chemokines [75]. Various chemokines trigger the emigration of dendritic cells, natural killer cells, $\mathrm{T}$ and $\mathrm{B}$ lymphocytes, leading to the obvious reduced growth of primary tumours and inhibition of tumour metastases [35, 75], Genes that express haemolysin $E$ recombinated with a highly hypoxia-inducible promoter increased tumour necrosis and reduced tumour growth by i.v. injection to 4T1 mice models [76].

The genes that can be chosen should maintain a high tumour to normal tissue ratio, resulting in the largest beneficial effect to patients. Meanwhile, genes delivered to the bacteria should have very low toxicity or even no influence on normal tissues. Ideally, the secreted substance or the activated drug should have a short circulating half-life and exert anti-tumour effects. It should be also shown that the synergetic toxic substances produced by bacteria do not influence the replication and persistence of the bacteria in tumours. It may happen that toxicities of expressing substances evolve from the modification of enzymes inside our bodies. If it comes to the situation that toxicities are too strong to sustain, it may be possible for patients to kill the bacteria and eliminate the toxicity using antibiotics. Even under the worst circumstances, the tumour would be exposed to far greater concentrations of the agent than normal tissue and presumably even limited exposure might have a substantial therapeutic benefit.

With the numerous effector genes that could be engineered into bacterial hosts, therapies could be extended to sequential or concurrent administration of similar or different bacteria that contain separate gene products. Demonstration of the central concept of selective intratumoural accumulation of bacteria in cancer patients can be expected to lead to a vast and novel repertoire of therapeutic options for the treatment of metastatic diseases.

\subsection{Listeria monocytogenes}

Listeria monocytogenes is a Gram-positive, facultative anaerobic, rod-shaped bacterium that has tumbling motility and is unable to form spores [77].

As a facultative anaerobic intracellular bacterium, L. monocytogenes lives and replicates within the cytosol of the host cell. It is one of the most virulent foodborne pathogens and is usually phagocytosed by antigen-presenting cells (APC). Once phagocytosed, the vast majority of the bacteria will be degraded inside the phagosome; however, about $10 \%$ of the bacteria are able to take advantage of virulent factors to break down the phagosome, which enables them to live freely in the host cytosol. These virulence factors mainly include liseriolysin O (LLO), which is a pore-forming haemolysin and phospholipase [75]. Once the bacterium enters the cytosol, actin polymerase A (Act A) is synthesised and L. monocytogenes starts to undergo rapid replication [78]. Act $\mathrm{A}$ is responsible for the recruitment and polymerisation of host cell actin, leading to the formation of a tail of actin, allowing for intracellular and intercellular movements [79]. Reorganisation of the cytoskeleton of host cells produces pseudopods containing L. monocytogenes that extend towards nearby cells, forming a double-membrane protrusions and infecting them [80]. Through this mechanism of spreading to other cells, L. monocytogenes is not exposed to the extracellular defences of the host, primarily accounting for why host cells do not develop a protective humoral response to it. The 
genes related to this cycle (i.e., prfA, plcA, hly, $m p l$, act $A, p l c B$, inl $A$, inlB, inl $C$ and $h p t$ ) are regulated by the transcriptional activator listeriolysin A (PrfA) [80]. It is possible that these virulence factors could enhance the immunogenicity of tumour-associated antigens, which are poorly immunogenic.

Considering the host immune response to $L$. monocytogenes, antibodies have been regarded for a long time to play no role in Listeria resistance, as there have been studies showing no protective effects after transferring the serum of Listeria-immune mice to naïve mice $[81,82]$. However, Unanue and colleagues have demonstrated a mechanism of intracellular neutralisation of the secreted virulence factor LLO via anti-LLO antibodies, taken up by macrophages through endocytosis, stored in endosomal compartments, waiting for an encounter with vacuole-containing Listeria [83]. Under these circumstances, the rate of $L$. monocytogenes escape from the phagosome is considerably reduced due to the opsonisation of LLO, thereby limiting intracellular growth. However, the amount of anti-LLO antibody used by Unanue and colleagues in these studies far exceeded physiological levels, putting into question to what extent the antibody can work well in neutralising the bacteria and demonstrating the humoral response may be too weak to provide effective protection to Listeria infection [83,84]. Although about $10 \%$ of L. monocytogenes can spread to nearby hosts, the rest of the bacteria are killed through a series of mechanisms mediated by our immune systems. Early resistance to $L$. monocytogenes is controlled mainly by macrophages, neutrophils and NK cells through various cytokines and chemokines [85]. Macrophages and neutrophils secrete IL-1, IL-6, IL-12, TNF- $\alpha$ and chemokines, recruiting natural killer (NK) cells that produce the macrophage-activating cytokine interferon- $\gamma$ (IFN- $\gamma)$; macrophages are responsible for further elimination of the pathogen [85]. After the innate immune response, most $L$. monocytogenes phagocytised by macrophages are degraded after fusion of the phagosome and lysosome and protein fragments are presented on major histocompatibility complex (MHC) II molecules induced by IFN- $\gamma$, which in turn present antigen to $\mathrm{CD}^{+} \mathrm{T}$ cells. The remaining $10 \%$ of L. monocytogenes escape from the phagolysosome and replicate inside the cytosol. The proteins produced here are degraded inside the proteasome and transported into the lumen of the endoplasmic reticulum (ER) through the transporter associated with antigen processing (TAP) and loaded onto MHC I molecules, thereby triggering the $\mathrm{CD}^{+} \mathrm{T}$ cell response [1]. Thus, L. monocytogenes is an ideal vector for delivering antigens to be processed and presented through both the MHC class I and II antigen processing pathways, which is a hallmark of host immunity to L. monocytogenes.

Owing to this property, unusual among intracellular pathogens, L. monocytogenes has been used as a vector to generate cell-mediated immunity against a wide range of pathogen antigens: influenza nucleoprotein (NP), HPV E7, HIV gag, simian immunodeficiency virus (SIV) env, tumour antigens tyrosinase-related protein (trp)-2 and human epidermal growth factor receptor (HER)-2/neu in preclinical experiments by normally i.v. injection. As a vaccine vector, the recombinant $L$. monocytogenes strains that have been developed for clinical uses are highly attenuated compared to wild type Listeria. With attenuation, the existing anti-vector immunity does not affect the therapeutic efficacy, which was verified by using a mutant Listeria missing the act $A$ gene as the antigen vector [78].

For the purposes of generating a $\mathrm{CD}^{+} \mathrm{T}$ cell response that is strong enough to kill tumour cells, the antigen that is responsible for triggering the immune response needs to be secreted outside the cell wall of the bacteria. In order to achieve this goal, $L$. monocytogenes is always engineered in a way by fusing target antigens with a secreted bacterial protein such as LLO to form a fusion protein. The promoter and signal sequence of LLO have been used to increase the expression of the target antigen [87-89]. In addition, the promoter and signal sequences of the secreted protein (LLO and ActA) have also been applied to enhance the expression of antigens integrated into chromosomes [90]. The expression of fusion proteins can be achieved using plasmids or recombined chromosomes. However, in a mouse model of HPV-derived cancer, the capacity of producing antigens using plasmid surpassed that chromosomes [88].

The first test of L. monocytogenes as a vector for cancer immunotherapy was carried out in a recombinant influenza NP (Lm-NP) against several tumour cell lines (CT26, Renca, B16-F10) [86,88,89]. Lm-NP protected the further challenge from tumours and induced complete regression of tumours expressing the same antigen. In addition, the anti-tumour effects of Lm-NP were analysed based on the immune response, showing the mutual participation of both $\mathrm{CD}^{+}$and $\mathrm{CD}^{+} \mathrm{T}$ cells, demonstrating a potent anti-tumour immunity triggered by recombinant $L$. monocytogenes $[89,91,92]$.

Based on this successful approach, $L$. monocytogenes was utilised to carry tumour-associated antigens HPV-16 E7, which can be either part of the Listeria genome following the haemolysin signal sequence (Lm-E7) or recombined into the plasmid with hly promotor followed by a non-haemolytic 
fusion of LLO-E7 (Lm-LLO-E7). Both of the strains were tested in established TC-1 tumours, derived from murine lung epithelial cells immortalised by HPV-16 E6 and E7 as well as transformed with activated oncogene ras [93]. Results showed that Lm-LLO-E7, rather than LLO-E7, induced the regression of E7-expressing tumours, indicating their significant differences between inducing immune response.

Despite the preclinical studies carried out in animal models, engineered L. monocytogenes are designed to express tumour-related antigens to trigger both innate and adaptive immunity clinically [94]. Attenuated L. monocytogenes vaccines expressing human papilloma virus (HPV) serotype 16 E7 (ADXS11-001), which is known to be overexpressed in HPV-related cervical cancer, have reached phase III clinical trials. Additionally, live-attenuated strains (ADXS31-142) that express prostatic specific antigen (PSA) and HER-2 expressing vaccines are in phase I/II clinical trials. Attenuated L. monocytogenes vaccines expressing mesothelin (ANZ-100/CRS-207) is being tested in mesothelioma, pancreatic, ovarian and Fallopian cancers [12].

\subsection{Bacillus}

Bacillus spp. is a genus of Gram-positive, rod-shaped, obligate aerobic or facultative anaerobic bacteria that can form spores [95]. This genus of bacteria is ubiquitous in nature and has the highest bioactivity in producing hundreds of metabolites [96]. These metabolites, including polypeptides, lipopeptides, polyketides, fatty acids and isocoumarin derived from Bacillus spp. are relatively abundant, exhibiting antifungal, anti-bacterial and even anti-tumour activities $[97,98]$.

Bacillus thuringiensis, isolated firstly as a pathogen in the sotto disease of the silkworm, Bombyx mori, has the ability to produce crystalline parasporal inclusions when sporulating [99]. The inclusions were found in the $20^{\text {th }}$ century to possess strong insecticidal effects to several insects [100]. Proteins inside the inclusions include $\delta$-endotoxins containing two families of insecticidal molecules, Cry and Cyt proteins [101]. Cry proteins are toxic specifically to insects, while Cyt proteins have wider cytolytic effects on vertebrate and invertebrate cells, including insect cells and mammalian erythrocytes [101].

Although B. thuringiensis has garnered the interest of scientists as an insecticide for decades, while recent studies reveal that the most common $B$. thuringiensis strains distributed in nature are non-insecticidal, raising the question as to whether the parasporal inclusions of non-insecticidal $B$. thuringiensis have specific bioactivities [102-104]. In this situation, a unique protein that is competent at targeting and killing cancer cells was identified.

In 1999, Mizuki et al. first screened the proteins inside the parasporal inclusions of 1744 strains of $B$. thuringiensis, containing 1700 Japanese isolates from Kyushu University and 44 reference types from the Institut Pasteur, Paris [105]. After a series of experiments including cytotoxicity assays, hemolysis assays, and insecticidal activity tests, Mizuki et al. selected and purified three Japanese isolates (84-HS-1-11, 89-T-26-17 and 90-F-45-14) that were neither insecticidal nor haemolytic, choosing for further exploration of their cancer cell toxicities [105]. After experiments on cancer-cell toxicities carried out in MOLT-4 (human leukaemia T cells), A549 (human lung cancer cells and HeLa (human uterine cervix cancer cells), all these strains exhibited strong cytocidal effects with variable toxic spectra and cytotoxicity [104]. Significantly, this experiment showed that the proteins of 84-HS-1-11 and 89-T-26-17 killed MOLT-4 cells more readily that normal T cells, suggesting the specificities of these proteins [105]. A year later, Mizuki et al. further obtained and characterised the protein from the inclusions of 84-HS-1-11, defining it as a toxin against human cancer cells, creating a new family of $\delta$-endotoxins of $B$. thuringiensis, named parasporins (PS) [106]. These are polypeptides with a predicted molecular weight of about $81 \mathrm{kDa}$, exhibiting cytocidal activities only when digested by proteases [106]. According to the Committee of Parasporin in Classification and Nomenclature (http://parasporin.fitc.pref.fukuoka. $\mathrm{jp} /$ ), the $81 \mathrm{kDa}$ parasporin characterised by Mizuki et al. in 2000 constitutes the PS1Aa1 family. Currently, this protein group is subdivided into six major families (PS1-PS6) [107]. These six families of proteins possess markedly different mechanisms against cancer cells and are activated by diverse terminal digestions [107]. Concerning the primitively identified parasprorin PS1Aa1, it has been confirmed to be toxic to HeLa, MOLT-4, HL-60 (promyelocytic leukaemia cell) and HepG2 (hepatocellular carcinoma) cells [108]. Further investigations revealed the possible mechanisms of PS1Aa1 in inducing the death of cancer cells. One of the most striking aspects was the early and rapid increase in the concentration of intracellular $\mathrm{Ca}^{2+}$, with no change in plasma membrane permeability, leading to the apoptosis of cancer cells [109]. Although the anti-cancer effects of $B$. thuringiensis have only been tested in vitro, they pave the ways for further investigations in treating cancer in vivo.

Beyond B. thuringiensis, another closely related strain is $B$. cereus. The only discrimination between them is the crystalline proteinaceous inclusions 
produced by B. thuringiensis [110]. It was originally regarded as a pathogen causing mild food poisoning due to the production of enterotoxins and emetic toxins; however, not all strains carry these genes [111]. Some strains of $B$. cereus have been identified as probiotics when administered in certain amounts orally [112]. Probiotics act as bioactive bacteria via metabolites that are capable of exhibiting anti-bacterial, anti-viral and anti-cancer effects [113]. Later, anti-cancer metabolites were obtained from an Indian $B$. cereus; fraction $\mathrm{BC} 1$ showed cytotoxicity against HepG2 cells by damaging DNA and triggering apoptosis in liver cancer cells [114]. However, in contrast to $B$. thuringiensis, this fraction did not contain proteins [114].

Other species of Bacillus, including B. subtilis, B. licheniformis and so on have also been discovered to induce cytotoxicity in cancer cells via various compounds [115-117]. All these observations indicate that, as a member of the phylum Firmicutes, Bacillus possesses strong bioactivity by producing various compounds that are toxic to cancer cells in vitro, providing direction for further investigations into the metabolites of Bacillus in the treatment of cancer.

\section{Tumour associated bacteria and their potential as oncolytic bacteria}

Clostridium spp., Bifidobacterium spp., $S$. typhimurium, Vibrio cholera, E. coli and L. monocytogenes have been observed to live in tumours; some of them have been applied to treat tumours using wild type or gene-modified strains [11,118-120]. S. pyogenes $O K-432$, a poorly virulent strain of type III group A $S$. pyogenes that can be treated with penicillin $\mathrm{G}$, has been used as agent to treat unresectable lymphangiomas. Mycobacterium bovis (BCG), acquired from a virulent strain of $M$. bovis by incubating it on a special medium, can be used to treat bladder cancer $[121,122]$. However, these two strains are mostly used after resection, acting as a complementary therapy to prevent recurrence.

Although existing oncolytic bacteria are under perpetual development, various challenges remain before they can be used successfully in the clinic. Problems include the concentration of toxic agents, targeting efficacy, bacterial toxicity, genetic instability and the combination with other anti-cancer therapies. Considering the concentration of toxic agents produced by bacteria in tumours, it should be high enough to exert therapeutic effects but not induce systemic toxicity. Targeting efficacy is influenced by tumour size, location and blood supply, which is distinct in different patients [34]. In metastatic tumours, bacteria can be amenable only when hypoxic regions exist. Although bacterial toxicities have been tested in animal models and human trials, the clinical safety is not assured due to the compromised immunity of cancer patients [43,72,123]. Another major problem is genetic instability, which may lead to the loss of functionalities including ineffectiveness or harmful phenotypes [124]. Meanwhile, determining the proper combination of bacteria with other traditional anti-cancer therapies will be vital for eliminating all tumour cells, including metastases $[49,125,126]$. Besides these problems, due to the distinct pathophysiology of different tumours, the selection of the most effective oncolytic bacteria against a certain type of tumour remains to be worked out. Oncolytic bacteria that have been tested in pre-clinical or clinical studies do not possess tumour specificities, which may be a hurdle for mass propagation in tumours. Therefore, eliminating the barriers of detected oncolytic bacteria and finding new oncolytic bacteria that possess tumour specificities are significant challenges.

Upon discovering oncolytic bacteria living in tumours, scientists found that some bacteria show specificities for certain types of tumours. F. nucleatum, which is indigenous to the oral cavity, has also been found in the gut microbiota and shows associations with colorectal carcinomas. Comparing the microbiome of colorectal carcinoma with that of a healthy colon, high enrichment of F. nucleatum in colonic tissues as well as stools of patients with colorectal adenomas and adenocarcinomas has been identified by metagenomic analyses [127]. Studies focusing on the mechanisms of $F$. nucleatum-associated colorectal cancers have revealed that the influence of tumourigenesis is not exerted by inducing inflammation or exacerbating colitis-associated colorectal cancer; rather, it is conducted by increasing the infiltration of $\mathrm{CD}_{11} \mathrm{~b}^{+}$ myeloid cells, a phenotype of myeloid-derived suppressor cells (MDSCs) in mice, which facilitate tumour growth and angiogenesis $[127,128]$. Meanwhile, studies have suggested that an increase of specific subsets of MDSCs accounts for effective potency by suppressing $\mathrm{CD}^{+} \mathrm{T}$ cells through the expression of arginase 1 and inducible nitric oxide synthase (iNOS) [127,129]. Previous studies have supported the idea that the tumour-associated neutrophils (TAN) promote tumour progression and metastasis by secreting elastase, thereby hydrolysing insulin receptor substrate 1 (IRS1), which blocks the interaction between phosphoinositide 3-kinase (PI3K) and platelet-derived growth factor receptor (PDGFR), thus activating the PDGFR-PI3K pathway [130]. Similarly, tumour-associated macrophages (TAM) have been verified as potent drivers of tumour angiogenesis [131]. The number of TAN and TAM 
increase significantly in F. nucleatum-fed mice by a mean of 13.4 times and 7.8 times, respectively, compared with controls, which indicates the modulatory effects of $F$. nucleatum to tumour-immune microenvironments, thereby promoting tumour progression and metastasis $[127,132]$.

After collecting supportive data from the mouse models, the immune cell biomarker genes related to $F$. nucleatum-associated colorectal cancers in human were identified. They include TAM-associated genes (IL-6, IL-8, CXCL10), MDSC-associated genes (CD33, IL-6), PTGS2 (COX2), IL-1 $\beta$ and TNF-a. Their expression levels correlate with the abundance of $F$. nucleatum in Fusobacterium-associated tumours and some of these genes suggest an NFKB-driven proinflammatory response (PTGS-2, IL-6, IL-8, IL-1 $\beta$, TNF- $\alpha$ ). This signalling pathway was later found to be more highly activated with a higher abundance of $F$. nucleatum in tumours [127].

In another similar situation, Straussman and colleagues detected the existence of bacteria in samples of human pancreatic ductal adenocarcinomas (PDACs) and showed that the most common species, accounting for more than half of all reads, belong to the Gammaproteobacterium, in which members of Enterobacteriaceae and Pseudomonadaceae are dominant [133]. Meanwhile, the potency of these bacteria in producing cytidine deaminase, an enzyme that has the ability to deaminate the chemotherapeutic drug gemcitabine, which mediates drug resistance, was confirmed in this study [133].

Based on the extensive tumour-specific colonisation of these bacteria, together with the rapid development of gene-modification techniques, bacteria living in certain types of tumour such as $F$. nucleatum and Gammaproteobacteria have excellent potential to be remoulded directionally for anti-tumour therapy. With the mechanisms of these bacteria in promoting tumour progression being revealed, the genes responsible for these processes can be selectively knocked out and recombined with genes expressing tumour-associated antigens, enzymes converting pro-drugs or agents toxic to tumours. By taking advantage of their characteristics of targeting and colonising certain types of tumours, incorporated with genetic modifications, bacteria living inside specific tumours have excellent potential for treating cancer and represent an innovative direction in complementary and direct anti-tumour therapy.

\section{Acknowledgements}

This work was supported by grants from the National Natural Science Foundation of China (81503364 to Tingtao Chen, and 31560264 to Tingtao
Chen), the Excellent Youth Foundation of the Jiangxi Scientific Committee (20171BCB23028 to Tingtao Chen), the Science and Technology Plan of the Jiangxi Health Planning Committee (20175526 to Tingtao Chen), the Science and Technology Project of Jiangxi (20181BBG70028 to Tingtao Chen and 20181BCB24003 to Tingtao Chen).

\section{Authors' contributions}

TC and YM designed the review; YW, WG, XW, $\mathrm{YZ}, \mathrm{CM}$ and $\mathrm{AB}$ searched the materials; TC, YW and $\mathrm{YM}$ analyzed the references and wrote the manuscript. All authors discussed the results and commented on the manuscript.

\section{Competing Interests}

The authors have declared that no competing interest exists.

\section{References}

1. Savage DC. Microbial Ecology of the Gastrointestinal Tract. Annu Rev Microbiol. 1977;31: 107-133. doi:10.1146/annurev.mi.31.100177.000543

2. Matsuoka K, Kanai T. The gut microbiota and inflammatory bowel disease. Seminars in Immunopathology. 2015; 37(1): 47-55. doi:10.1007/s00281-014-0454-4

3. Royce R a, Thorp J, Granados JL, Savitz D a. Bacterial vaginosis associated with HIV infection in pregnant women from North Carolina. [Internet]. Journal of acquired immune deficiency syndromes and human retrovirology: official publication of the International Retrovirology Association. 1999; 20(4): 382-6. Available: http://www.ncbi.nlm.nih.gov/pubmed/10096583

4. Lee $\mathrm{WH}$, Chen HM, Yang SF, Liang C, Peng CY, Lin FM, et al. Bacterial alterations in salivary microbiota and their association in oral cancer. Sci Rep. 2017; 7(1): 16540. doi:10.1038/s41598-017-16418-x

5. Fry L, Baker BS. Triggering psoriasis: the role of infections and medications. Clin Dermatol. 2007; 25: 606-615. doi:10.1016/j.clindermatol.2007.08.015

6. Clemente JC, Ursell LK, Parfrey LW, Knight R. The impact of the gut microbiota on human health: An integrative view. Cell. 2012. pp. 1258-1270. doi:10.1016/j.cell.2012.01.035

7. Borre YE, O'Keeffe GW, Clarke G, Stanton C, Dinan TG, Cryan JF. Microbiota and neurodevelopmental windows: implications for brain disorders. Trends in molecular medicine. 2014; 20(9): 509-518. doi:10.1016/j.molmed.2014.05.002

8. Heikkilä MP, Saris PEJ. Inhibition of Staphylococcus aureus by the commensal bacteria of human milk. J Appl Microbiol. 2003;95: 471-8. doi:10.1046/j.1365-2672.2003.02002.x

9. Aagaard K, Ma J, Antony KM, Ganu R, Petrosino J, Versalovic J. The placenta harbors a unique microbiome. Sci Transl Med. 2014;6. doi:10.1126/scitranslmed.3008599

10. Tedeschi GG, Amici D, Paparelli M. Incorporation of nucleosides and amino-acids in human erythrocyte suspensions: Possible relation with a diffuse infection of mycoplasms or bacteria in the L form. Nature. 1969. pp. 1285-1286. doi:10.1038/2221285a0

11. Van Mellaert L, Barbé S, Anné J. Clostridium spores as anti-tumour agents. Trends in Microbiology. 2006. doi:10.1016/j.tim.2006.02.002

12. Riglar DT, Silver PA. Engineering bacteria for diagnostic and therapeutic applications. Nature Reviews Microbiology. 2018. doi:10.1038/nrmicro.2017.172

13. Nemunaitis J, Cunningham C, Senzer N, Kuhn J, Cramm J, Litz C, et al. Pilot trial of genetically modified, attenuated Salmonella expressing the E. coli cytosine deaminase gene in refractory cancer patients. Cancer Gene Ther. 2003; doi:10.1038/sj.cgt.7700634

14. Loeffler M, Le'Negrate G, Krajewska M, Reed JC. IL-18-producing Salmonella inhibit tumor growth. Cancer Gene Ther. 2008; doi:10.1038/cgt.2008.48

15. Chao Ma, Jiangbing Zhou, Xiaolu Yin, Chunfa Jie, Dongming Xing, Lijun Du and Zhang Y. Mycobacterium tuberculosis culture supernatant induces cancer cell apoptosis and cell cycle arrest. The Open Cancer Journal. 2008; 2: 31-41.

16. Fidler IJ. The pathogenesis of cancer metastasis: The "seed and soil" hypothesis revisited. Nature Reviews Cancer. 2003; 3(6): 453-458. doi:10.1038/nrc1098

17. Umer B, Good D, Anné J, Duan W, Wei MQ. Clostridial spores for cancer therapy: Targeting solid tumour microenvironment. Journal of Toxicology. 2012; 2012: 1-8. doi:10.1155/2012/862764

18. Munn LL. Aberrant vascular architecture in tumors and its importance in drug-based therapies. Drug Discovery Today. 2003; 8(9): 396-403. doi:10.1016/S1359-6446(03)02686-2 
19. Mowday AM, Guise CP, Ackerley DF, Minton NP, Lambin P, Dubois LJ, et al. Advancing Clostridia to Clinical Trial: Past Lessons and Recent Progress. Cancers. 2016; 8(7): 1-14. doi:10.3390/cancers8070063

20. Dvorak HF. Tumors: Wounds That Do Not Heal:Similarities between tumor stroma generation and wound healing. N Engl J Med. 1987; 315: 1650-1659. doi:10.1158/2326-6066.CIR-14-0209

21. Brown JM. Tumor microenvironment and the response to anticancer therapy. Cancer Biol Ther. 2002; 1: 453-458. doi:10.4161/cbt.1.5.157

22. GRAY LH, CONGER AD, EBERT M, HORNSEY S, SCOTT OC. The concentration of oxygen dissolved in tissues at the time of irradiation as a factor in radiotherapy. $\mathrm{Br} \mathrm{J}$ Radiol. 1953; 26(312): 638-648. doi:10.1259/0007-1285-26-312-638

23. Lee $\mathrm{C}-\mathrm{H}$. Engineering bacteria toward tumor targeting for cancer treatment: current state and perspectives. Appl Microbiol Biotechnol. 2012; 93: 517-523. doi:10.1007/s00253-011-3695-3

24. Baban CK, Cronin M, Hanlon DO, Sullivan GCO, Tangney M. Bacteria as vectors for gene therapy of cancer. 2010; 385-394. doi:10.4161/bbug.1.6.13146

25. Coley WB. Contribution to the knowledge of sarcoma. Annals of Surgery 1891; 14: 199-220.

26. Coley WB. Late results of the treatment of inoperable sarcoma by the mixed toxins of erysipelas. and Bacillus prodigiosus. Journal of the American Medical Association. 1898; XXXI(9): 456.

27. McCarthy EF. The toxins of William B. Coley and the treatment of bone and soft-tissue sarcomas. Iowa Orthop J. 2006; 26: 154-8.

28. Sukhan A. The invasion-associated type III secretion system of Salmonella typhimurium: Common and unique features. Cellular and Molecular Life Sciences. 2000; 57(7): 1033-1049. doi:10.1007/PL00000743

29. Galán JE, Collmer A. Type III secretion machines: Bacterial devices for protein delivery into host cells. Science. 1999; 284(5418): 1322-1328. doi:10.1126/science.284.5418.1322

30. Norimatsu M, Chance V, Dougan G, Howard CJ, Villarreal-Ramos B. Live Salmonella enterica serovar Typhimurium (S. Typhimurium) elicit dendritic cell responses that differ from those induced by killed S. Typhimurium. Vet Immunol Immunopathol. 2004; 98: 193-201. doi:10.1016/j.vetimm.2003.12.008

31. Wyant TL, Tanner MK, Sztein MB. Salmonella typhi flagella are potent inducers of proinflammatory cytokine secretion by human monocytes. Infect Immun. 1999; 67: 3619-24. Available: http://www.pubmedcentral.nih.gov/ articlerender.fcgi?artid $=116552 \&$ tool $=$ pmcentrez\&rendertype $=$ abstract

32. CEA Winslow, J broadhurst, RE Buchanan, C Krumwiede, JR., LA Rogers, GHS. The families and genera of the bacteria. J Bacteriol. 1917; 2(5): 505-566.

33. Hatheway CL. Toxigenic Clostridia. Clin Microbiol Rev. 1990; 3: 66-98.

34. Pawelek JM, Low KB, Bermudes D. Bacteria as tumour-targeting vectors. Lancet Oncology. 2003; 4(9): 548-556. doi:10.1016/S1470-2045(03)01194-X

35. Torrey JC, Kahn MC. The treatment of flexner-jobling rat carcinomas with bacterial proteolytic ferments. J Cancer Res. 1927; 11: 334-376. doi:10.1158/jcr.1927.334

36. Connell HC. The Study and Treatment of Cancer by Proteolytic Enzymes: Preliminary Report. Can Med Assoc J. 1935; 33: 364-70. Available: http://www.pubmedcentral.nih.gov/articlerender.fcgi?artid=1561462\&tool= pmcentrez\&rendertype $=$ abstract

37. Parker RC, Plummer HC, Siebenmann CO, Chapman MG. Effect of Histolyticus Infection and Toxin on Transplantable Mouse Tumors. Exp Biol Med. 1947; 66: 461-467. doi:10.3181/00379727-66-16124

38. Malmgren RA, Flanigan CC. Localization of the Vegetative Form of Clostridium tetani in Mouse Tumors Following Intravenous Spore Administration. Cancer Res. 1955; 15: 473-478.

39. Möse JR, Möse G. Oncolysis by Clostridia. I. Activity of Clostridium butyricum (M-55) and Other Nonpathogenic Clostridia against the Ehrlich Carcinoma. Cancer Res. 1964; 24: 212-216.

40. Thiele EH, Arison RN, Boxer GE. Oncolysis by Clostridia. III. Effects of Clostridia and Chemotherapeutic Agents on Rodent Tumors. Cancer Res. 1964; 24 : 222-233.

41. Schlechte $H$, Schwabe $K$, Mehnert WH, Schulze $B$, Bräuniger $H$. Chemotherapy for tumours using clostridial oncolysis, antibiotics and cyclophosphamide: model trial on the UVT 15264 tumour. Arch Geschwulstforsch. $\quad$ 1982; 52: 41-48. Available: http://europepmc.org/abstract/med/7082130

42. Gericke D, Dietzel F, Ruster I. Further progress with oncolysis due to local high frequency hyperthermia, local X-irradiation and apathogenic clostridia. J Microw Power. 1979; 14: 163-166. doi:10.1080/16070658.1979.11689147

43. Carey RW, Holland JF, Whang HY, Neter E, Bryant B. Clostridial oncolysis in man. Eur J Cancer. 1967; 3: 37-46. doi:10.1016/0014-2964(67)90060-6

44. Heppner F, Möse JR. The liquefaction (oncolysis) of malignant gliomas by a non pathogenic Clostridium. Acta Neurochir (Wien). 1978; 42: 123-125. doi:10.1007/BF01406639

45. Minton NP, Mauchline ML, Lemmon MJ, Brehm JK, Fox M, Michael NP, et al. Chemotherapeutic tumour targeting using clostridial spores. FEMS Microbiol Rev. 1995; 17(3): 357-364. doi:10.1111/j.1574-6976.1995.tb00219.x

46. Schlechte $\mathrm{H}$, Elbe B. Recombinant plasmid DNA variation of clostridium oncolyticum - model experiments of cancerostatic gene transfer. Zentralblatt fur Bakteriol Mikrobiol und Hyg - Abt 1 Orig A. 1988; 268: 347-356. doi:10.1016/S0176-6724(88)80019-1

47. Lemmon MJ, Van Zijl P, Fox ME, Mauchline ML, Giaccia AJ, Minton NP, et al. Anaerobic bacteria as a gene delivery system that is controlled by the tumor microenvironment. Gene Ther. 1997; 4(8): 791-796. doi:10.1038/sj.gt.3300468
48. Nuyts S, Van Mellaert L, Theys J, Landuyt W, Bosmans E, Anné J, et al. Radio-responsive recA promoter significantly increases TNFa production in recombinant clostridia after 2 Gy irradiation. Gene Ther. 2001; 8(15): 1197-1201. doi:10.1038/sj.gt.3301499

49. Dang LH, Bettegowda C, Huso DL, Kinzler KW, Vogelstein B. Combination bacteriolytic therapy for the treatment of experimental tumors. Proc Natl Acad Sci. 2001; 98(26): 15155-15160. doi:10.1073/pnas.251543698

50. Schell MA, Karmirantzou M, Snel B, Vilanova D, Berger B, Pessi G, et al. The genome sequence of Bifidobacterium longum reflects its adaptation to the human gastrointestinal tract. Proc Natl Acad Sci. 2002; 99(22): 14422-14427. doi:10.1073/pnas.212527599

51. Turroni F, Milani C, Duranti S, Ferrario C, Lugli GA., Mancabelli L, et al. Bifidobacteria and the infant gut: an example of co-evolution and natural selection. Cell Mol Life Sci. 2018; 75(1), 103-118. doi:10.1007/s00018-017-2672-0

52. Harmsen HJ, Wildeboer-Veloo AC, Raangs GC, Wagendorp AA, Klijn N, Bindels JG, et al. Analysis of intestinal flora development in breast-fed and formula-fed infants by using molecular identification and detection methods. J

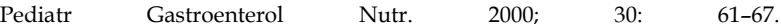
doi:10.1097/00005176-200001000-00019

53. Adams MR, Marteau P. On the safety of lactic acid bacteria from food. International Journal of Food Microbiology. 1995; 27(2-3): 263-264. doi:10.1016/0168-1605(95)00067-T

54. Yazawa K, Fujimori M, Amano J, Kano Y. therapy : Selective localization and growth in hypoxic tumors. 2000; 7: 269-274.

55. NAKAMURA T, SASAKI T, FUJIMORI M, YAZAWA K, KANO Y, AMANO J, et al. Cloned Cytosine Deaminase Gene Expression of Bifidobacterium longum and Application to Enzyme/Pro-drug Therapy of Hypoxic Solid Tumors. Biosci Biotechnol Biochem. 2014; 66: 2362-2366. doi:10.1271/bbb.66.2362

56. Sasaki T, Fujimori M, Hamaji Y, Hama Y, Ito KI, Amano J, et al. Genetically engineered Bifidobacterium longum for tumor-targeting enzyme-prodrug therapy of autochthonous mammary tumors in rats. Cancer Sci. 2006; 97(7): 649-657. doi:10.1111/j.1349-7006.2006.00221.x

57. Fujimori M. Genetically engineered bifidobacterium as a drug delivery system for systemic therapy of metastatic breast cancer patients. Breast cancer. 2006; 13: 27-31. doi:10.2325/jbcs.13.27

58. Zeuthen LH, Christensen HR, Frøkiaer H. Lactic Acid Bacteria Inducing a Weak Interleukin-12 and Tumor Necrosis Factor Alpha Response in Human Dendritic Cells Inhibit Strongly Stimulating Lactic Acid Bacteria but Act Synergistically with Gram-Negative Bacteria. Clin Vaccine Immunol. 2006; 13: 365-375. doi:10.1128/CVI.13.3.2006.365

59. Murray GL, Attridge SR, Morona R. Regulation of Salmonella typhimurium lipopolysaccharide $\mathrm{O}$ antigen chain length is required for virulence; identification of FepE as a second Wzz. Mol Microbiol. 2003; 47(5): 1395-1406. doi:10.1046/j.1365-2958.2003.03383.x

60. Lüderitz O, Freudenberg MA, Galanos C, Lehmann V, Rietschel ET, Shaw DH Lipopolysaccharides of Gram-Negative Bacteria. Microbial Membrane lipids. 1982; 17: 79-151. doi:10.1016/S0070-2161(08)60309-3

61. Slauch JM, Mahan MJ, Michetti P, Neutra MR, Mekalanos JJ. Acetylation (O-factor 5) affects the structural and immunological properties of Salmonella typhimurium lipopolysaccharide $\mathrm{O}$ antigen. Infect Immun. 1995; 63(2): 437-441. doi:10.1016/j.antiviral.2010.01.002

62. Wallis TS, Galyov EE. Molecular basis of Salmonella-induced enteritis. $\begin{array}{llll}\text { Molecular } & \text { Microbiology. } & \text { 2000; } & \text { 36(5): }\end{array}$ doi:10.1046/j.1365-2958.2000.01892.x

63. Pawelek JM, Low KB, Bermudes D. Tumor-targeted Salmonella as a novel anticancer vector. Cancer Res. 1997; 57: 4537-4544. doi:10.1097/00008390-199706001-00491

64. Bacon GA, Burrows TW, Yates M. The effects of biochemical mutation on the virulence of Bacterium typhosum: the virulence of mutants. Br J Exp Pathol. 1950; 31: 714-724. Available: http://www.pubmedcentral.nih.gov/ articlerender.fcgi? artid=2073388\&tool=pmcentrez\&rendertype $=$ abstract

65. Bacon GA, Burrows TW. The effects of biochemical mutation on the virulence of Bacterium typhosum: the induction and isolation of mutants. Br J Exp Pathol. 1950; 31(6): 703-713.

66. Somerville JE, Cassiano L, Darveau RP. Escherichia coli msbB gene as a virulence factor and a therapeutic target. Infect Immun. 1999; 67: 6583-6590.

67. Low KB, Ittensohn M, Le T, Platt J, Sodi S, Amoss M, et al. Lipid a mutant Salmonella with suppressed virulence and $\mathrm{TNFa}$ induction retain tumor-targeting in vivo. Nat Biotechnol. 1999; 17: 37-41. doi:10.1038/5205

68. Bacon GA, Burrows TW, Yates M. The effects fo biochemical mutaion on the virulence of Bacterium typhosum: the loss of virulence of certain mutants. 1951; 32(2): 85-96.

69. Chen T, Zhao X, Ren Y, Wang Y, Tang X, Tian P, et al. Triptolide modulates tumour-colonisation and anti-tumour effect of attenuated Salmonella encoding DNase I. Appl Microbiol and Biotechnol. 2018. doi:10.1007/s00253-018-9481-8

70. Chen T, Tian P, Huang Z, Zhao X, Wang H, Xia C, et al. Engineered commensal bacteria prevent systemic inflammation-induced memory impairment and amyloidogenesis via producing GLP-1. Appl Microbiol Biotechnol. 2018; 102(17): 7565-7575. doi:10.1007/s00253-018-9155-6

71. Rosenberg SA, Spiess PJ, Kleiner DE. Antitumor effects in mice of the intravenous injection of attenuated Salmonella typhimurium. J Immunother. 2002; 25: 218-225. doi:10.1097/00002371-200205000-00004

72. Lee KC, Zheng L, Luo X, Clairmont C, Fischer J, Margitich D, et al. Comparative Evaluation of the Acute Toxic Effects in Monkeys , Pigs and Mice 
of a Genetically Engineered Salmonella Strain ( VNP20009) Being Developed as an Antitumor Agent. International Journal of Toxicology. 2000; 19(1): 19-25.

73. Chen T, Zhao X, Ren Y, Wang Y, Tang X, Tian P, Wang H, Xin H. Triptolide modulates tumour-colonisation and anti-tumour effect of attenuated Salmonella encoding DNase I. Appl Microbiol Biotechnol. 2018: 1-11.

74. Zheng JH, Nguyen VH, Jiang SN, Park SH, Tan W, Hong SH, et al. Two-step enhanced cancer immunotherapy with engineered Salmonella typhimurium secreting heterologous flagellin. Sci Transl Med. 2017; 9(376): eaak9537. doi:10.1126/scitranslmed.aak9537

75. Loeffler M, Le'Negrate G, Krajewska M, Reed JC. Attenuated Salmonella engineered to produce human cytokine LIGHT inhibit tumor growth. Proc Natl Acad Sci USA. 2007; 104(31): 12879-12883. doi:10.1073/pnas.0701959104

76. Ryan RM, Green J, Williams PJ, Tazzyman S, Hunt S, Harmey JH, et al. Bacterial delivery of a novel cytolysin to hypoxic areas of solid tumors. Gene Ther. 2009; 16(3): 329-339. doi:10.1038/gt.2008.188

77. Farber JM, Peterkin PI. Listeria monocytogenes, a foodborne pathogen. Microbiol Rev. 1991; 55(3): 476-511. doi:10.1104/pp.110.161547

78. Dussurget O, Pizarro-Cerda J, Cossart P. Molecular determinants of Listeria monocytogenes virulence. Annu Rev Microbiol. 2004; 58: 587-610. doi:10.1146/annurev.micro.57.030502.090934

79. Pistor S, Chakraborty T, Niebuhr K, Domann E, Wehland J, Chakraborty1 T, et al. The ActA protein of Listeria monocytogenes acts as a nucleator inducing reorganization of the actin cytoskeleton. EMBO J. 1994; 13(4): 758-763. doi:10.1002/j.1460-2075.1994.tb06318.x

80. Dussurget O, Pizarro-cerda J, Cossart P. Molecular determinants of Listeria monocytogenes virulence. Annu Rev Micobiol. 2004; 58: 587-610. doi:10.1146/annurev.micro.57.030502.090934

81. Mackaness GB. The relationship of delayed hypersensitivity to acquired cellular resistance. British Medical Bulletin. 1967; 23(1): 52-542.

82. Osebold JW, Sawyer MT. Immunization Studies on Listeriosis in Mice. J Immunol. 1957; 78(4): 262-268.

83. Edelson BT, Unanue ER. Intracellular antibody neutralizes Listeria growth. Immunity. 2001; 14: 503-512. doi:10.1016/S1074-7613(01)00139-X

84. Edelson BT, Cossart P, Unanue ER. Cutting edge: paradigm revisited: antibody provides resistance to Listeria infection. J Immunol. 1999; 163: 4087-4090.

85. Unanue ER. Studies in listeriosis show the strong symbiosis between the innate cellular system and the T-cell response. Immunological Reviews. 1997; 158(1): 11-25. doi:10.1111/j.1600-065X.1997.tb00988.x

86. Koch M, Ko A, Kursar M, Mittru H, Herma M, Kaufmann SHE. Protective T cell response against intracellular pathogens in the absence of Toll-like receptor signaling via myeloid differentiation factor 88 . 2004; 16: 415-421. doi:10.1093/intimm/dxh047

87. Singh R, Dominiecki ME, Jaffee EM, Paterson Y. Fusion to Listeriolysin O and Delivery by Listeria monocytogenes Enhances the Immunogenicity of HER-2/neu and Reveals Subdominant Epitopes in the FVB/N Mouse. J Immunol. 2005; 175: 3663-3673. doi:10.4049/jimmunol.175.6.3663

88. Dalet A, Vigneron N, Stroobant V, Hanada K -i., Van den Eynde BJ. Splicing of Distant Peptide Fragments Occurs in the Proteasome by Transpeptidation and Produces the Spliced Antigenic Peptide Derived from Fibroblast Growth Factor-5. J Immunol. 2010; 184(6): 3016-3024. doi:10.4049/jimmunol.0901277

89. Pan ZK, Ikonomidis G, Lazenby A, Pardoll D, Paterson Y. A recombinant Listeria monocytogenes vaccine expressing a model tumour antigen protects mice against lethal tumour cell challenge and causes regression of established tumours. Nat Med. 1995; 1: 471-477. doi:10.1038/nm0595-471

90. Shen H, Slifka MK, Matloubian M, Jensen ER, Ahmed R, Miller JF. Recombinant Listeria monocytogenes as a live vaccine vehicle for the induction of protective anti-viral cell-mediated immunity. Proc Natl Acad Sci U S A. 1995; 92: 3987-3991. doi:10.1073/pnas.92.9.3987

91. Pan ZK, Weiskirch LM, Paterson Y. Regression of established B16F10 melanoma with a recombinant Listeria monocytogenes vaccine. Cancer Res. 1999; 59: 5264-5269.

92. Pan ZK, Ikonomidis G, Paterson Y, Pardoll D. Regression of Established Tumors in Mice Mediated by the Oral Administration of a Recombinant Listeria monocytogenes Vaccine. Cancer Res. 1995; 55: 4776-4779.

93. Lin KY, Guarnieri FG, Staveley-O'Carroll KF, Levitsky HI, August JT, Pardoll $\mathrm{DM}$, et al. Treatment of established tumors with a novel vaccine that enhances major histocompatibility class II presentation of tumor antigen. Cancer Res. 1996; 56: 21-26. doi:8548765

94. Bessis N, GarciaCozar FJ, Boissier MC. Immune responses to gene therapy vectors: Influence on vector function and effector mechanisms. Gene Therapy. 2004; 11 (Suppl 1):S10-S17. doi:10.1038/sj.gt.3302364

95. Baruzzi F, Quintieri L, Morea M, Caputo L. Antimicrobial compounds produced by Bacillus. spp. and applications in food. Commun Curr Res Educ Top Trends Appl Microbiol Méndez-Vilas.2011; 1102-1111.

96. Bérdy, J. Bioactive Microbial Metabolites. The Journal of Antibiotics. 2005; 58(1): 1-2 6 .

97. Sharma A, Meena KR, Kanwar SS. Annals of Pharmacology and Pharmaceutics. Microbial Lipopeptides and their Medical Applications. 2017; 2(24): 1126

98. Hamdache A, Lamarti A, Aleu J, Collado IG. Non-peptide metabolites from the genus bacillus. J Nat Prod. 2011;74(4),893-899 doi:10.1021/np100853e

99. Ishiwata, S. On a kind of severe flacherie (sotto disease). Dainihon Sanshi Kaiho. 1901;114: 1- 5.
100. Lambert B, Peferoen M. Promise of Insecticidal Bacillus thuringiensis Facts and mysteries. about a successful biopesticide. Bioscience. 2012;42: 112-122.

101. Knowles BH, White PJ, Nicholls CN and Ellar DJ: A broad- spectrum cytolytic toxin from Bacillus thuringiensis var. kyushuensis. Proc Royal Soc London B. 1992;248: 1-7.

102. Ohba M, Aizawa K. Insect toxicity of Bacillus thuringiensis isolated from soils of Japan. J Invertebr Pathol. 1986;47: 12-20. doi:10.1016/0022-2011(86)90158-8

103. Hastowo, S., Lay, B.W. and Ohba, M. Naturally occurring Bacillus thuringiensis in Indonesia. Journal of Applied Bacteriology. 1992;73: 108-113.

104. Ohba, M., Yu, Y.M. and Aizawa, K. Occurrence of non-insecticidal Bacillus thuringiensis flagellar serotype 14 in the soil of Japan. Systematic and Applied Microbiology. 1988;11: 85-89.

105. Mizuki E, Ohba M, Akao T, Yamashita S, Saitoh H and Park YS: Unique activity assosated with non-insecticidal Bacillus thuringiensis parasporal inclusions: in vitro cell-killing action on human cancer cells. J Appl Microbiol. 1999;86: 477-486.

106. Mizuki E, Park YS, Saitoh H, Yamashita S, Akao T, Higuchi K and Ohba M: Parasporin, a. human leukemic cell-recognizing parasporal protein of Bacillus thuringiensis. Clin Diagn Lab Immunol. 2000;7: 625-634.

107. Okassov A, Nersesyan A, Kitada S, Ilin A. Parasporins as new natural anticancer agents: A. review. Journal of B.U.ON.: official journal of the Balkan Union of Oncology 2015;20(1): 5-16.

108. Katayama H, Yokota H, Akao T, Nakamura O, Ohba M, Mekada E and Mizuki E: Parasporin-1, a novel cytotoxic protein to human cells from non-insecticidal parasporal inclusions of Bacillus thuringiensis. J Biochem. 2005;137: 17-25.

109. Katayama H, Kusaka Y, Yokota H, Akao T, Kojima M, Nakamura O, et al. Parasporin-1, a. novel cytotoxic protein from Bacillus thuringiensis, induces $\mathrm{Ca} 2+$ influx and a sustained elevation of the cytoplasmic $\mathrm{Ca} 2+$ concentration in toxin-sensitive cells. J Biol Chem. 2007;282: $7742-7752$ doi:10.1074/jbc.M611382200

110. Biomolecules A, Tamanna U, Shishir A, Nargis S, Hoq M. Bacillus spp: Attractive Sources of. Anti-cancer and Anti-proliferative Biomolecules. 2018;1: 33-45.

111. Hoa, N.T., Baccigalupi, L., Huxham, A., Smertenko, A., Van, P.H., Ammendola, S., Ricca, E., Cutting, S.M. Characterization of Bacillus species used for oral bacteriotherapy and bacterioprophylaxis of gastrointestinal disorders. Appl. Environ. Microbiol. 2000; 66: 5241-5247.

112. FAO \& WHO. Guidelines for the evaluation of probiotics in food. Food Agric Organ / World. Heal Organ. 2002. doi:10.1111/j.1469-0691.2012.03873

113. Seo, H.-R., Kim, J.-Y., Kim, J.-H., \& Park, K.-Y. Identification of Bacillus cereus in a Chungkukjang That Showed High Anticancer Effects Against AGS Human Gastric Adenocarcinoma Cells. Journal of Medicinal Food. 2009;12(6): 1274-1280. doi:10.1089/jmf.2009.0081

114. Kumar, M. L. V., Thippeswamy, B., \& Raj, P. V. Cytotoxicity and Anticancer Studies of Bacillus cereus and Bacillus pumilus Metabolites Targeting Human Cancer Cells 1. Applied Biochemistry and Microbiology. 2014;50(6): 619-623.

115. Aboul-Ela, H. M., Shreadah, M. A., Abdel-Monem, N. M., Yakout, G. A., \& Soest, R. W. M. van. Isolation, cytotoxic activity and phylogenetic analysis of Bacillus sp. bacteria associated with the red sea sponge Amphimedon ochracea. Advances in Bioscience and Biotechnology. 2012;3: 815-823.

116. Seerangaraj, V., KannanSuruli, Vijayakumar, U., Meganathan, B., Seerangaraj, V., Selvam, S., Selvaraj, J. Isolation and Characterization of Bioactive Compounds from Bacillus cereus and Bacillus subtilis from Oreochromis mossambicus and Labeo rohita. International Journal of Pharmaceutical Sciences Review and Research. 2017;43(2): 71-77.

117. Dahech, I., Belghith, K. S., Belghith, H., \& Mejdoub, H. Partial purification of a Bacillus. licheniformis levansucrase producing levan with antitumor activity. Internation- al Journal of Biological Macromolecules. 2012;51(3): 329-335.

118. Łukasiewicz K, Fol M. Microorganisms in the Treatment of Cancer: Advantages and Limitations. J Immunol Res. 2018; 2018:1-8. doi:10.1155/2018/2397808

119. Vassaux G, Nitcheu J, Jezzard S, Lemoine NR. Bacterial gene therapy strategies. Journal of Pathology. 2005; 208(2): 290-298. doi:10.1002/path.1865

120. Castellarin M, Warren RL, Freeman JD, Dreolini L, Krzywinski M, Strauss J, et al. Fusobacterium nucleatum infection is prevalent in human colorectal carcinoma. Genome Res. 2012; 22(2): 299-306. doi:10.1101/gr.126516.111

121. Olivieri C, Nanni L, De Gaetano AM, Manganaro L, Pintus C. Complete Resolution of Retroperitoneal Lymphangioma with a Single Trial of OK-432 in an Infant. Pediatr Neonatol. 2016; 57(3): 240-243. doi:10.1016/j.pedneo.2013.06.011

122. Herr HW, Morales A. History of Bacillus Calmette-Guerin and Bladder Cancer: An Immunotherapy Success Story. J Urol. 2008; 179(1): 53-56. doi:10.1016/j.juro.2007.08.122

123. Toso JF, Gill VJ, Hwu P, Marincola FM, Restifo NP, Schwartzentruber DJ, et al. Phase I study of the intravenous administration of attenuated Salmonella typhimurium to patients with metastatic melanoma. J Clin Oncol. 2002; 20(1): 142-152. doi:10.1200/JCO.20.1.142

124. Patyar S, Joshi R, Byrav DSP, Prakash A, Medhi B, Das BK. Bacteria in cancer therapy: A novel experimental strategy. Journal of Biomedical Science. 2010; 17(1): 21. doi:10.1186/1423-0127-17-21

125. Jiang SN, Phan TX, Nam TK, Nguyen VH, Kim HS, Bom HS, et al. Inhibition of tumor growth and metastasis by a combination of escherichia coli-mediated cytolytic therapy and radiotherapy. Mol Ther. 2010; 18(3): 635-642. doi:10.1038/mt.2009.295 
126. Dang LH, Bettegowda C, Agrawal N, Cheong I, Huso D, Frost P, et al. Targeting vascular and avascular compartments of tumors with C. novyi-NT and anti-microtubule agents. Cancer Biol Ther. 2004; 3(3): 326-337. doi:10.4161/cbt.3.3.704

127. Kostic AD, Chun E, Robertson L, Glickman JN, Gallini CA, Michaud M, et al. Fusobacterium nucleatum Potentiates Intestinal Tumorigenesis and Modulates the Tumor-Immune Microenvironment. Cell Host Microbe. 2013; 14(2): 207-215. doi:10.1016/j.chom.2013.07.007

128. Ghajar CM. On leukocytes in mammary development and cancer. Cold Spring Harb Perspect Biol. 2012; 4(5): a013276-a013276. doi:10.1101/cshperspect.a013276

129. Gabrilovich DI, Nagaraj S. Myeloid-derived suppressor cells as regulators of the immune system. Nature Reviews Immunology. 2009; 9(3): 162-174. doi:10.1038/nri2506

130. Houghton AMG, Rzymkiewicz DM, Ji H, Gregory AD, Egea EE, Metz HE, et al. Neutrophil elastase-mediated degradation of IRS-1 accelerates lung tumor growth. Nat Med. 2010; doi:10.1038/nm.2084

131. Mantovani A, Sica A. Macrophages, innate immunity and cancer: balance, tolerance, and diversity. Current Opinion in Immunology. 2010; 22(2): 231-237. doi:10.1016/j.coi.2010.01.009

132. Qian BZ, Pollard JW. Macrophage Diversity Enhances Tumor Progression and Metastasis. Cell. 2010; 141(1): 39-51. doi:10.1016/j.cell.2010.03.014

133. Geller LT, Barzily-Rokni M, Danino T, Jonas OH, Shental N, Nejman D, et al. Potential role of intratumor bacteria in mediating tumor resistance to the chemotherapeutic drug gemcitabine. Science. 2017; 357(6356): 1156-1160. doi:10.1126/science.aah5043 